\title{
A 3D INFORMATION SYSTEM FOR THE DOCUMENTATION OF ARCHAEOLOGICA L EXCAVATIONS
}

\author{
P. Ardissone ${ }^{\mathrm{a},}$, L. Bornaz ${ }^{\mathrm{a}}$, G. Degattis ${ }^{\mathrm{b}}$, R. Domaine ${ }^{\mathrm{b}}$
}
${ }^{\text {a }}$ Ad Hoc 3D Solutions srl, Fraz. La Roche 8, 11020, Gressan, Aosta, Italy - (paolo.ardissone;leandro.bornaz)@adhoc3d .com
${ }^{\mathrm{b}}$ Regione Autonoma della Valle d'Aosta - Superintendence for Cultural Heritage of Aosta Valley, Piazza Narbonne 3, 11100 Aosta, Italy - (g.degattis;r.domaine)@ regione.vda.it

\section{Commission}

KEY WORDS: Laser scanners, Photogrammetry, 3d Management System, Archaeology, Conservation, 4D GIS

\begin{abstract}
:
Documentation of archaeological and cultural heritage sites is at the heart of the archaeological process and an important component in cultural heritage research, presentation and restorations.

In 2012 the Superintendence of Cultural Heritage of Aosta Valley - IT (Soprintendenza per i Beni e le Attività Culturali della Region e Autonoma Valle d'Aosta) carried out a complex archaeological excavation in a composite archaeological context, situated an urban background: the Aosta city centre.

This archaeological excavation has been characterized by the classical urban archaeological issues: little space, short time, complex s tratigraphy. Moreover the investigations have come out several structures and walls that required safety and conservation measures. Ad hoc 3D solutions carried out a complete 3D survey of the area in 10 different time/situations of the Archaeological digs, chosen in collaborations with the archaeological staff. In this way a multi temporal 3D description of the site has been provided for the archaeo logical analysis and for the project of the restorations activities.

The 3D surveys has been carried out integrating GPS, laser scanner technology and photogrammetry. In order to meet the needs of th e site, and its complex logistics and to obtain products that guarantee the high quality and detail required for archaeological analysis, we have developed different procedures and methodologies:

hdr imaging for 3D model with correct, consistent and uniform colours,

noise filtering and people filtering, for the removal of interference between laser instrument and object of the survey,

Advanced laser scanner triangulation, in order to consider both artificial and natural tie points, for a correct registration of a huge am ount of scans.

Single image orientation on 3D data, in order to integrate the laser data with data coming from digital photogrammetry (faster on the field than the laser scanner survey, than used in certain situations)

The results of all these methodologies and procedures will be presented and described in the article.

For the documentation of the archaeological excavations and for the management of the conservation activities (condition assessmen t, planning, and conservation work). Ad Hoc 3D solutions has costumized 2 special plug-ins of its own software platform Ad Hoc: A $\mathrm{d}$ Hoc Archaeology and Ad Hoc Conservation.

The software platform integrates a 3D database management system. All information (measurements, plotting, areas of interests...) a re organized according to their correct 3D position. They can be queried using attributes, geometric characteristics or their spatial pos ition.

The Ad Hoc Archaeology plug-in allows archeologists to fill out UUSS sheets in an internal database, put them in the correct locatio $\mathrm{n}$ within the 3D model of the site, define the mutual relations between the UUSS, divide the different archaeological phases. A simple interface will facilitate the construction of the stratigraphic chart (matrix), in a 3D environment as well (matrix 3D).

The Ad Hoc Conservation plug-in permits conservators and restorers to create relationships between the different approaches and des criptions of the same parts of the monument, i.e.: between stratigraphyc units or historical phases and architectural components and/o $\mathrm{r}$ decay pathologies. The 3D DBMS conservation module uses a codified terminology based on "ICOMOS illustrated glossary of ston e deterioration" and other glossary. Specific tools permits restorers to compute correctly surfaces and volumes. In this way decay ext ension and intensity can be measured with high precision and with an high level of detail, for a correct time and costs estimation of e ach conservation step.
\end{abstract}




\section{LASER SCANNER AND CULTURAL HERITAGE}

\section{Today laser scanner use in cultural heritage}

Increasingly, culture experts use and exploit laser scanner data. This meeting could potentially lead to excellent results in terms of data quality, quantity and reliability. Almost always, however, we are witnessing a dissatisfaction and disappointment on the part of the culture experts, who have to handle complex and huge data, and they are unable to verify $3 \mathrm{~d}$ models accuracy and reliability.

In general, laser scanners are used only for generating video and point clouds images. Usually we can see published sections and profiles or laser orthoviews, which are well different in terms of quality from accurate orthophotos, that should be used in the cultural domain. Theese products that show the cultural site in 3D do not really help the experts in the management and the study of the site from an archaeological or conservative point of view.

The $3 \mathrm{~d}$ pointclouds are sometimes heavy elaborated with graphical modeling procedures, in order to generate multimedia products, which are however very expensive and time consuming.

\section{Authors experience}

The authors' experience in the use of laser scanner begins in 2000. According to us, most of the problems arise because correct data treatment, acquisition and management processing is sometimes missing. In fact laser scanners are often sold as very easy to use tools, and not as complex topographical instruments. At the same time the data treatment distributed software are typically system that comes from the mechanics field, which greatly differs in terms of requirements from the geomatics or cultural heritage field.

The typical problems arising using laser scanner are:

1. Coordinate system management. Usually in the cultural heritage field the laser scanner data must be georeferrenced, but almost no one manages the reference systems integration in the correct way. During a laser scanner acquisition several scans are carried out. Then the scans are usually aligned and registered in a local reference system. The georeferencing is carried out after the scan registration process using as ground control points some targets knows in a cartographic reference system (in Italy usually UTM ED50 or UTM WGS84). The problem of the georeferencing process is that all the cartographic reference systems are a $2 \mathrm{~d}$ deformed representation of a $3 \mathrm{~d}$ world. So, when we try to georeference the already aligned pointcloud, with $3 \mathrm{~d}$ real distances between targets, on a cartographic system, using the same targets, these ones are deformed by the projection rules, so we made a mistake. In some cases this error is negligible (due to small digitalized area, small orthometric heights and position on the cartographic projection) but in most cases these errors are not so small and usually are completely not considered. The result is a not well georeferenced model.

All these considerations are even important if terrestrial and aerial laser scanner are both used to describe an archaeological (or environmental) site. TLS acquire in a local real reference system, ALS usually acquire data using a cartoghaphic (and so deformed) reference system. The two point clouds cannot simply merged, and a simple point cloud alignement (e.g. ICP, that minimize the alignment error) is not the correct way to obtain the final result. Ad Hoc 3D solved this very serious and often forgotten problem some years ago developing a rigorous merging system. All the scans carried out are registered and georeferenced in the same time using the right cartographic, geodetical and shape rules. This method allow to obtain a more correct $3 \mathrm{~d}$ point cloud and allow to transform pointcloud between reference systems very easy and in real time.

2. Data filtering. The laser scanner are affected by different types of noise: the instrument noise, the vegetation, the light conditions, the people presence, a.s.o.. Laser scanner data must be filtered to obtain a good final result.
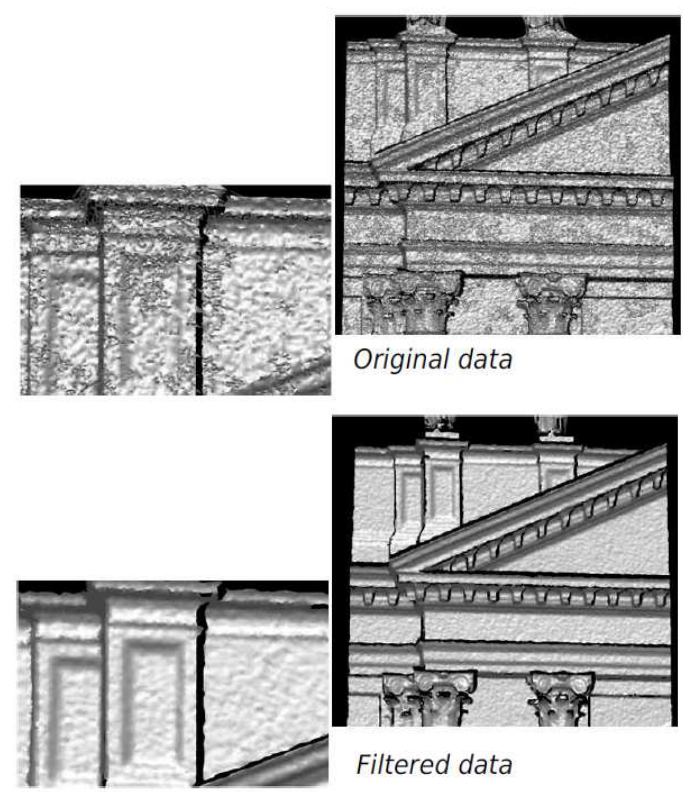

Figure 1. Filtering noise in laser scanner acquisitions
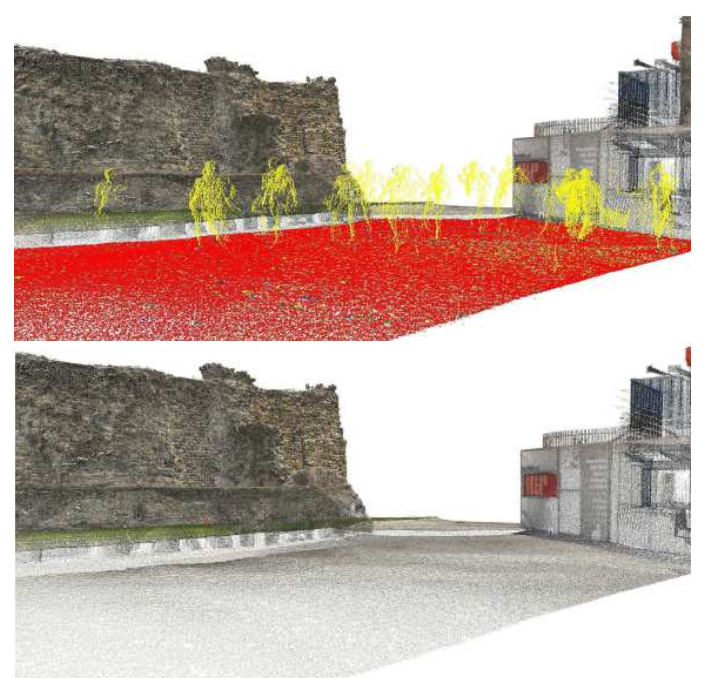

Figure 2. People filtering in laser scanner acquisitions

The filtering is not just a simple smoothing algorithm. Ad Hoc 3D developed different filtering algorithms, depending of what noise have to be removed. What we obtain from the original point cloud, is a noise-free $3 \mathrm{~d}$ model, that represent the correct starting point to obtain any final result, like video, true orthophotos, $3 \mathrm{~d}$ surface models, ... 
3.

Final product delivered to users. Usually the final products obtained using laser scanner are the 3D poincloud, orthoviews, true orthophotos and video or images.

First of all it is very important to not confuse orthoview with true orthophotos. The orthoview are simply a $2 \mathrm{D}$ visualisation, along an orthographic point of view, of a $3 \mathrm{~d}$ pointcloud. The true orthophoto is instead a complex 2D photographic representation, obtained between the integration of a 3D pointcloud and a complete photogrammetric survey of the object. The true orthophoto is more complex and need more time to be generated. The final result obtained is really better, compared to an orthoview.

In addition more classical final products obtained with laser scanner are profiles and sections.

4. Management system. All the final products obtained with laser scanner are usually delivered to final users separately. The $3 \mathrm{~d}$ point cloud in one file, the true orthophoto in one other files, the profiles and section in on other file, and so on. The archaeologists and conservators use these files separately to carried out their studies.

Ad Hoc 3D studied a system to recombine all these final products. An integrated management system (Ad Hoc) allow users to obtain more information from the acquired data. The system allow to exploit 3D laser scanner surveys data quickly and easily, by an easy $2 \mathrm{~d}$ or $3 \mathrm{~d}$ interface. It can manage different data types (solid images, 3D models, orthophotos ...) on which the user can use several tools for geometric and radiometric analysis, 3D drawing and to show and hide areas of interest.

The Ad Hoc management system transform the laser scanner survey in a real 3D information system (3D GIS). All information are organized according to their correct 3D position. It is possible to query it by attributes, geometric characteristics and spatial position.

In addition, with the developed management system and the correct management of reference systems explained before, a laser scanner survey has a huge value added, in case it can to combine data with other types of investigation. With geophysics, for example, to return the description of "above" and "below" and their mutual relations, with interferometry to properly position the highlighted changes and describe the context in which they occur. Even with the design and $3 \mathrm{D}$ rendering, to see together the parts that already exist and those that will be built.

\section{A NEW WAY TO USE LASER 3D DATA IN CULTURAL HERITAGE}

Documentation of archaeological and cultural heritage sites is at the heart of the archaeological process and an important component in cultural heritage research, presentation and restorations.

For the documentation of the archaeological excavations and for the management of the conservation activities (condition assessment, planning, and conservation work) Ad Hoc 3D solutions has customized 2 special plug-ins of its own software platform and management system Ad Hoc: Ad Hoc
Archaeology and Ad Hoc Conservation.

The software platform integrates a 3D database management system. All information (measurements, plotting, areas of interests...) is organized according to its correct 3D position. Then it can be queried using attributes, geometric characteristics or spatial position.

\section{Archaeological plugin}

Archaeologists are today accustomed to the use of orthophotos, photoplans and data deriving from laser scanner or photogrammetry. Even if they use modern techniques to obtain $2 \mathrm{~d}$ or $3 \mathrm{~d}$ views of the excavations, in their daily work they still create UUSS and drawings of the site manually.

All the acquired data is then elaborated in many different systems and usually the final results are inserted in a $2 \mathrm{~d} 1 / 2$ GIS system.

In this workflow the final result is not real connected to the $3 \mathrm{~d}$ model, and the system is not dynamic. After obtaining the final result some graphic elaborations have to be carried out to show the final result on the original data (for example texturing an modelling poin clouds to obtain a 3D simplify model or mapping the orthophotos with UUSS or subdividing different archaeological phases)

The Ad Hoc Archaeology plug-in allows archaeologists to work in a unique system strictly connected to $3 \mathrm{D}$ point clouds, true orthophotos, ... The system allows archaeologist to fill out UUSS sheets in an internal database, put them in the correct location within the 3D model of the site, draw their shapes, define the mutual relations between the UUSS, divide the different archaeological phases. A simple interface will facilitate the construction of the stratigraphic chart (matrix), in a $3 \mathrm{D}$ environment as well (matrix 3D).

First of all the archaeologists can insert new UUSS. They can use orthophotos or the $3 \mathrm{D}$ model to georeference each single UUSS.

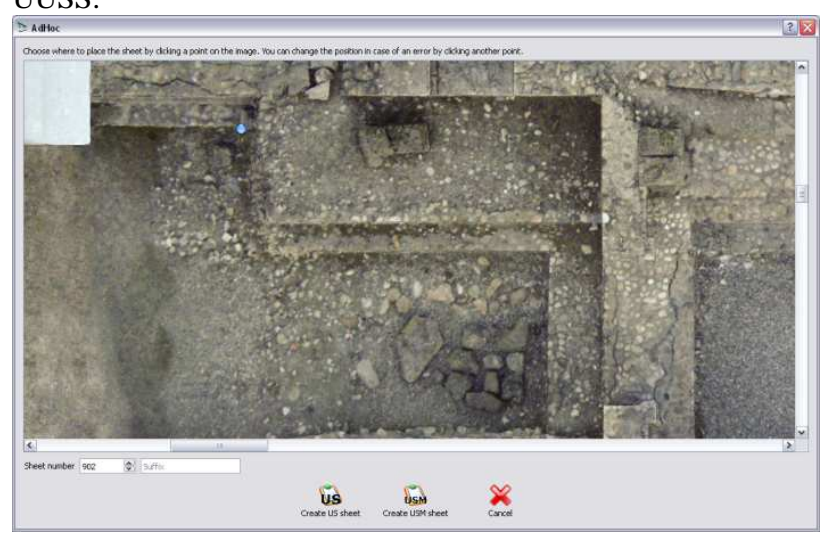

Figure 3. New UUSS

Automatically the system associate at the UUSS the correct 3D spatial position and show the data entry form. To correctly georeference and organize all the UUSS of the site not only the 3D model is considered. One or more true orthophotos and series of additional localization fields can be defined. These fields allow user to subdivide the 3D space in many and more simple and subsequent parts: area, sector, room, wall / ceiling / floor.

This organization has been defined after an important confrontation between surveyors experts, archaeologists and conservators because it can be considered as the central link that allows to connect data coming from these three different fields and to perform cross analysis between archaeological and restoration/conservation results.

This data subdivision allow to better manage UUSS when the 
sheets number is very huge.
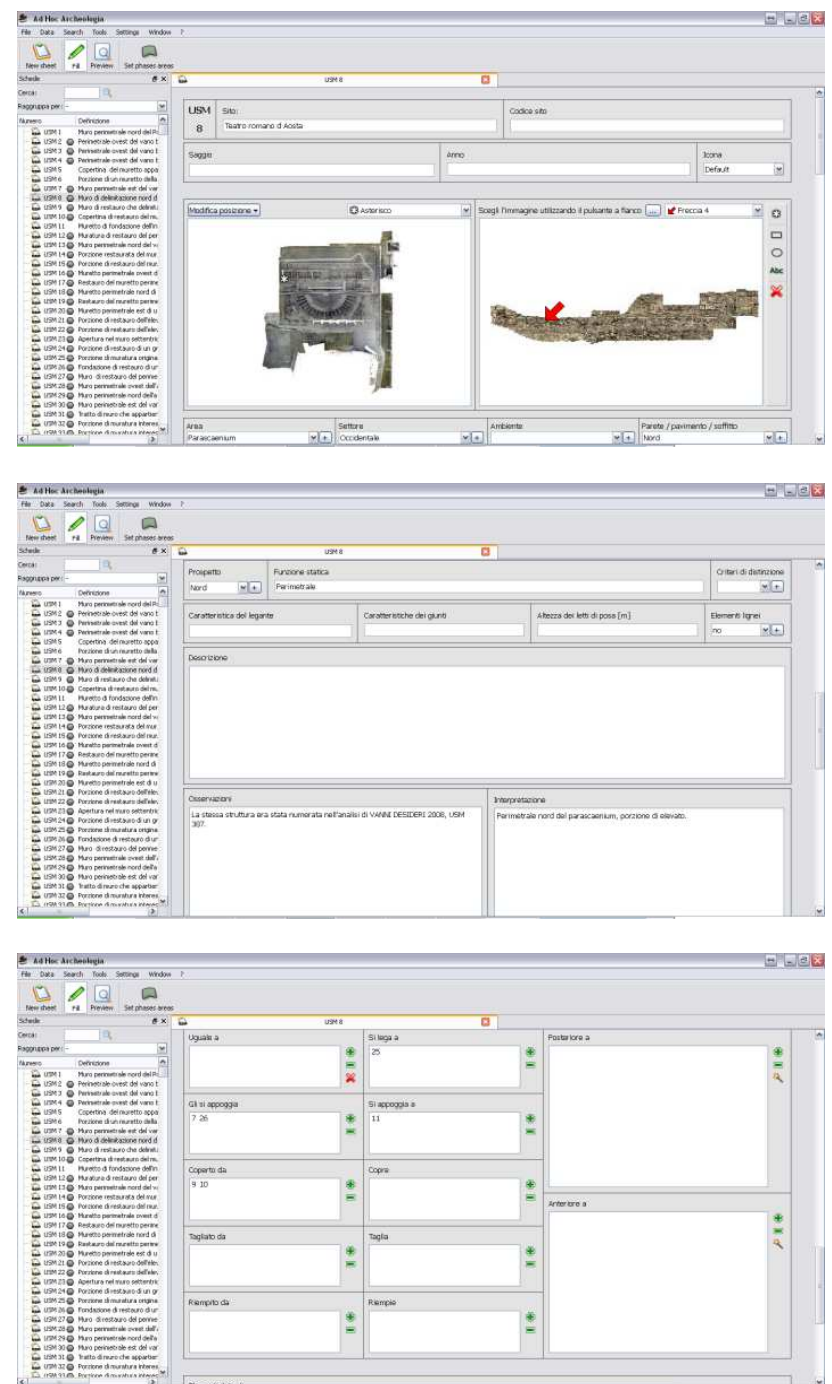

Figure 4. UUSS data Entry

During data entry all the operation that can be carried out automatically by the system, have been automated. In this way, for example, the archaeologists are not obliged to reopen an already compiled data sheet to modify and add relations between UUSS. An intelligent system that works in the background quickly and continuously check if the entry data is correct or affected by some incongruent relations. In this case an error message is showed whit the incongruence that has been found and the correction can be applied.

Archaeologist, during the excavations, produces a series of handmade drawings. These drawings are a very important component of the excavation. The Ad hoc management system has been conceived to connect all the available data to give to users as much information as possible. In this context a specific drawings data entry has been developed. Archaeologist can import drawing in the system and georeference them correctly with few clicks.

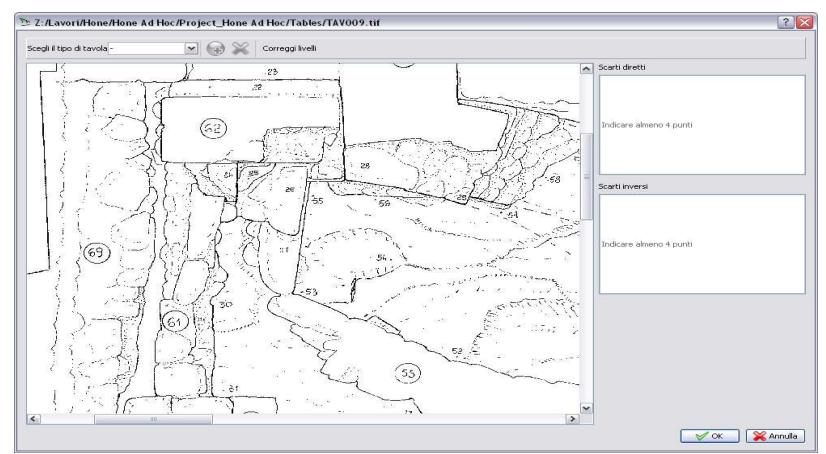

Figure 5. Handmade drawing georeferencing

Each handmade drawing, after the georeferencing, can be used to carry out planar measurements or can be integrated in the 3D model to better understand the archaeological phases. In this way the new 3D data acquired with laser scanner systems are perfectly connected with the classical excavation documents. Images and photo-mosaics can be used too.

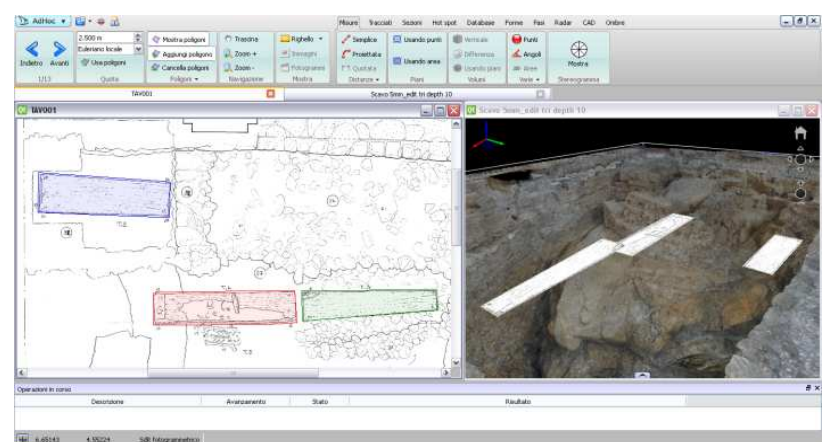

Figure 6. Handmade drawing integrated in $3 \mathrm{~d}$ point cloud

The management system allow to integrate $3 \mathrm{D}$ point cloud, true orthophotos, handmade drawings, UUSS, a.s.o., Using this principle each UUSS can be associated to a specific area of the object or site. To do this true orthophotos or handmade drawings can be used. Users can define, during the excavations, the exact area to which the single UUSS refers.

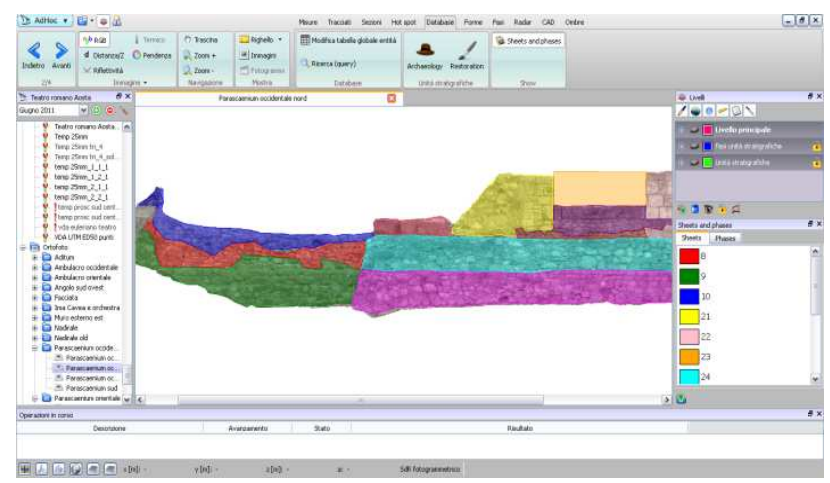

Figure 7. UUSS on a true orthophoto

This operation can be done on field, when the UUSS have been filled, or at the end of the work. It can also not be required.

Each associated area can be modified in any moment, if users change idea about the area.

After or during data entry the archaeological matrix can be displayed and built. All the relations between UUSS are already inserted so the matrix drawing is assisted by the system. 


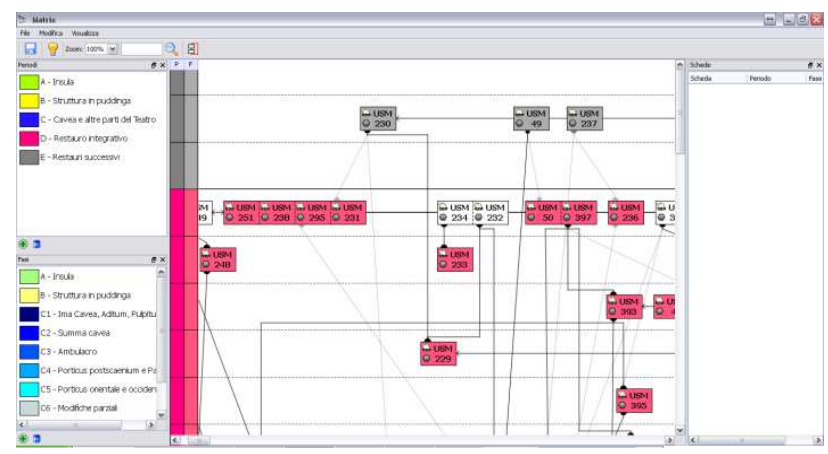

Figure 8. Matrix editing

The system allow to check if all the UUSS are already inserted in the matrix, in order to avoid loss of data.

In the matrix it is possible to associate period and phases to one sheet or to a group of UUSS. Automatically each UUSS are updated with the new information derived from the matrix.

As each UUSS is georeferenced and linked to true orthophotos, drawings and $3 \mathrm{D}$ models it is possible to build a $3 \mathrm{D}$ matrix view, according to $3 \mathrm{~d}$ georeferencing and timing.

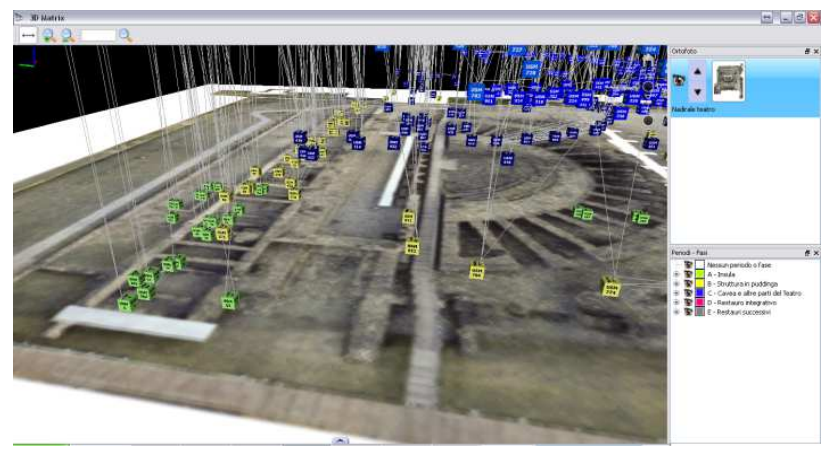

Figure 9.3D matrix

At the end of data entry and matrix building, the system allow archaeologist to obtain PDF of the UUSS, the plotted matrix, a $3 \mathrm{~d}$ view of the matrix and $3 \mathrm{D}$ models, true orthophotos and drawings mapped with archaeological information.

Also phase plans can be generated directly from the system integrating all the inserted informations and in particular true orthophotos and handmade drawings.

The potentiality and the innovation of this approach is due to the system dynamicity. Using this system it is possible to obtain some phase plans already during the excavation or data filling. In addition, the system allow to carried out all the changes that are necessary, even at the end of the process. For example, if archaeologist, at the end of data entry, after the final phases definition, due to a specific discovery or additional studies, realize that a new phase or archeological period have to be considered, they just need to add new information in Ad Hoc archaeological plugin and automatically the system provide all necessary changes.

Moreover, all the inserted data is organized in a database, so all the data can be queried. This is very important for local administration in particular, as they can extract from a huge amount of data what they need very quickly.

Is very important to underline that the developed plugin is a management system that allow archaeologists to carry out a set of operation directly in an unique environment. The developed method do not replace the archaeologist work, only simplify the management of all the data and allows to keep together all the excavation data.
This plugin has been developing following to Surintendence of Aosta requirements and needs.

\section{Conservation plugin}

Developing the archaeology plugin, the needs of restorers have been taken in consideration too. This was very important in order to obtain an unique system able to allow archaeologists and restorers to work individually but allowing a comparison and an overlap of the results obtained at all times.

In the conservation field the requirements are completely different but some connections can be found between archaeologists and conservators. The most important connection between them is in particular the object (or the site), so its digital copy, the reference system and the final digital products. For example archaeologist and conservator use to map their studies on the same ortophotos.

Using a complete management system allows the surintendence and the local administrations to have a more accurate complete description of the site. The Ad Hoc Conservation plug-in permits conservators and restorers to create relationships between the different approaches and descriptions of the same parts of the monument, i.e.: between stratigraphyc units or historical phases and architectural components and/or decay pathologies. The 3D DBMS conservation module uses a codified terminology based on "ICOMOS illustrated glossary of stone deterioration" and other glossary. Specific tools permits restorers to compute correctly surfaces and volumes. In this way, decay extension and intensity can be measured with high precision and with an high level of detail, for a correct time and costs estimation of each conservation step. (for more detail about this module see C. Pedelì, AN INTERDISCIPLINARY CONSERVATION MODULE FOR CONDITION SURVEY ON CULTURAL HERITAGES WITH A 3D INFORMATION SYSTEM - CIPA 2013)

\section{Ad Hoc system}

Ad hoc is the 3D management system that allows the archaeological and conservation plugins to work together. Ad Hoc is a software platform delivered by Ad Hoc 3D solutions.

It is not a software for laser data treatment, but a suite that requires 3D data and survey results created with specific geomatic skills.

\section{AOSTA PRAETORIA CASE STUDY}

In 2012 the Superintendence of Cultural Heritage of Aosta Valley - IT (Soprintendenza per i Beni e le Attività Culturali della Regione Autonoma Valle d'Aosta) carried out a complex archaeological excavation in a composite archaeological context, situated an urban background: the Aosta city centre.

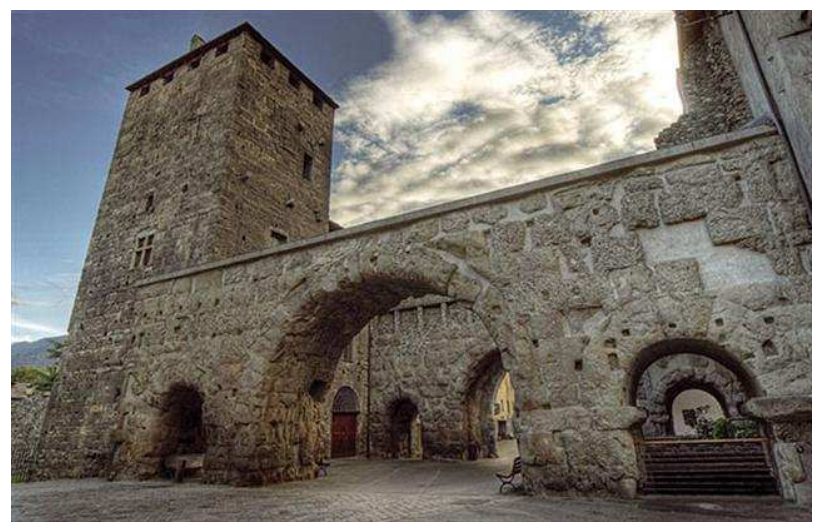


Figure 10. The "Porta Praetoria" in Aosta

All the procedures described before about the archaeological plugin have been adopted during the excavations by the company in charge of the work: Archeos (http://www.archeosaosta.it/)

More than 10 laser scanner and photogrammetric surveys have been carried out in different time/situations during the excavations.

In this way a multi temporal 3D description of the site has been provided for the archaeological analysis and for the project of the restorations activities.

The 3D surveys has been carried out integrating GPS, laser scanner technology and photogrammetry. In order to meet the needs of the site, and its complex logistics and to obtain products that guarantee the high quality and detail required for archaeological analysis, we have developed different procedures and methodologies:

- $\quad$ hdr imaging for 3D model with correct, consistent and uniform colors,

- noise filtering and people filtering, for the removal of interference between laser instrument and object of the survey,

- $\quad$ Advanced laser scanner triangulation, in order to consider both artificial and natural tie points, for a correct registration of a huge amount of scans.

For the documentation of the archaeological excavations and for the management of the conservation activities (condition assessment, planning, and conservation work) the Ad Hoc methodology was used.

During excavation a lot of handmade drawing have been realized. All the drawings have been inserted in the system and all the UUSS have been filled digitally during excavations.

Actually the excavations are not still finished so we are not able to show results about this specific site.

However, parallel to the excavation, the conservators of the Aosta surintendence are using the conservation module on the same data (for more detail about this activity see C. Pedelì, AN INTERDISCIPLINARY CONSERVATION MODULE FOR CONDITION SURVEY ON CULTURAL HERITAGES WITH A 3D INFORMATION SYSTEM - CIPA 2013)

\section{References from Journals:}

L Bornaz, AM Lingua, F Rinaudo, Terrestrial laser scanning: increasing automation for engineering and heritage applications - GIM INTERNATIONAL, 2003

\section{References from Other Literature:}

Pedelì, C., 2013. AN INTERDISCIPLINARY CONSERVATION MODULE FOR CONDITION SURVEY ON CULTURAL HERITAGES WITH A 3D INFORMATION SYSTEM. In: Recording, Documentation and Cooperation for Cultural heritage, XXIV International CIPA 2013 Symposium, Strasburgm 2-6 September 2013.

L Bornaz, F Rinaudo, Terrestrial laser scanner data processing, Proceedings of XX ISPRS Congress, Istanbul, 2004

F Rinaudo, L Bornaz, P Ardissone 3D Hight accuracy survey and modelling for cultural heritage documentation and restoration - VAST 2007-Future technologies to empower heritage ..., 2007

L Bornaz, CM Porporato, NEW TRENDS IN HIGH RESOLUTION SURVEY FOR THE CULTURAL HERITAGE METRIC SURVEY APPLYCATIONS FOR RESTORATION

\section{- 37TH CIPA INTERNATIONAL WORKSHOP DEDICATED ON E-DOCUMENTATION AND STANDARDISATION IN CULTURAL HERITAGE}

\section{Acknowledgements}

As Ad Hoc 3D Solution team we have to thank:

- Mauro Cortelazzo that support us in the first and big developing of the archaeology plugin and in particular for his efforts in sharing with us his experience in the archaeological field, for testing and explain to us all the archaeological needs.

- Cinzia Joris (Archeos Aosta) for all the subsequent developments, testing and new proposal .

Many thanks to the local administration of Aosta, and all the surintendance staff that give us many important information to develop the system.

A special thanks to Corrado Pedelì for the time, patience, and for sharing with us the development of the restoration plugin 